\title{
Estudiantes EPG decimocuarta cohorte
}

\author{
CARLOS JOSE MUÑOZMONTOYA \\ Ingeniero Topógrafo, Universidad del Valle \\ Tecnólogo en Topografía, Universidad Distrital \\ MAGDA LILIANA PEREZ CASTRO \\ Ingeniera Catastral y Geodesia, Universidad Distrital \\ JORGERIVERAPABÓN \\ Administrador del Medio Ambiente, \\ Universidad Tecnológica de Pereira \\ MARTAELENAMONTAÑO \\ Ingeniera Civil, Universidad del Cauca \\ MARIAALEJANDRA TABORDACARO \\ Licenciada en Ciencias Sociales, Universidad Pedagógica Nacional \\ BERNARDO ANTONIO MORENO \\ Abogado, Universidad Nacional de Colombia
}

